\title{
Implicaciones socio-ambientales de la explotación artesanal de áridos en el municipio de Sumbe, Cuanza Sul, Angola
}

\author{
Januário Cacilda-André1*, José Francisco Lastra-Rivero²
}

doi: http://dx.doi.org/10.18273/revbol.v41n3-2019006 @ (1)

Forma de citar: Cacilda-André, J., y Lastra-Rivero, J.F. (2019). Implicaciones socio-ambientales de la explotación artesanal de áridos en el municipio de Sumbe, Cuanza Sul, Angola. Boletín de Geología, 41(3), 127 143. doi: 10.18273/revbol.v41n3-2019006.

\section{RESUMEN}

La minería artesanal y a pequeña escala en el municipio de Sumbe, provincia Cuanza Sul, Angola, se ha practicado durante los últimos 20 años, por muchas familias necesitadas de sustento económico y de materiales para construir sus viviendas, provocando daños al medio ambiente de diversa magnitud. Esta investigación tiene como objetivo identificar y evaluar los impactos ambientales que se producen por las explotaciones de áridos mediante la minería artesanal y a pequeña escala en este territorio, con énfasis en la detección de los principales problemas socio-ambientales generados por estas actividades mineras y la necesidad de establecer un marco regulatorio basado en la explotación sostenible de estos recursos mediante una estrategia de ordenamiento ambiental. Para ello se aplicaron métodos de campo, instrumentos de encuesta-entrevista, y métodos para la identificación, caracterización y evaluación de los impactos ambientales. Los resultados obtenidos permiten esclarecer las implicaciones que estas actividades mineras tienen sobre el desarrollo socio-económico sostenible, además de denunciar el uso indiscriminado de mujeres y niños, todo ello estimulado por la alta demanda de los materiales extraídos para construcciones civiles y los beneficios económicos que reportan con inmediatez. La anarquía e irracionalidad derivada de estas acciones provocan impactos ambientales moderados e inestabilidad de los componentes ambientales. Entre las medidas que se proponen para el ordenamiento ambiental de este tipo de actividad minera se consideran: a) la creación de cooperativas; b) el establecimiento de normas que regulen el otorgamiento de concesiones mineras artesanales, con eliminación de la explotación de la población femenina e infantil; c) la aplicación de programas de educación ambiental a la población; d) la elaboración de instrumentos de control para las explotaciones de áridos; e) la implementación de normativas en las que se declaren las responsabilidades individuales y colectivas para la restauración del medio ambiente dentro de un marco legal.

Palabras clave: áridos; impacto ambiental; minería artesanal y a pequeña escala; desarrollo sostenible; ordenamiento ambiental.

\section{Socio-environmental implications of the artisanal exploitation of aggregates in the municipality of Sumbe, Cuanza Sul, Angola}

\begin{abstract}
Artisanal and small-scale mining in the municipality of Sumbe, Cuanza Sul province, Angola, has been practiced for the past 20 years, by many families in need of economic support and materials to build their homes, causing damage to the environment of diverse magnitude. The objective of this research is to identify and evaluate the environmental impacts produced by arid exploitations through artisanal and small-scale mining in this territory, with emphasis on the detection of the main socio-environmental problems generated by these mining activities and the need to establish a regulatory framework based on the sustainable exploitation of these resources through an environmental management strategy. For this, field methods, survey-interview instruments and methods for the identification, characterization and evaluation of environmental impacts were applied. The results obtained allow to clarify the implications that these mining activities have on sustainable socio-economic development, as well as to denounce the indiscriminate use of women and children, all stimulated by the high demand of extracted materials for civil constructions and the economic benefits that they report immediately. The anarchy and irrationality derived from these actions cause moderate environmental impacts and instability of environmental components. Among the measures that are proposed for the environmental ordering of this type of mining activity are considered: a) the creation of cooperatives; b) the establishment of norms that regulate the granting of artisanal mining concessions, with the elimination of the exploitation of the female and child population; c) the application of environmental education programs to the population; d) the development of control instruments for arids mining; e) the implementation of regulations that declare individual and collective responsibilities for the restoration of the environment within a legal framework.
\end{abstract}

Keywords: arids; environmental impact; artisanal and small-scale mining; sustainable development; environmental ordering.

\footnotetext{
${ }^{1}$ Instituto Superior de Ciências de Educação do Cuanza Sul, República de Angola. (*) januario1973@gmail.com

${ }^{2}$ Universidad de Pinar del Río, Pinar del Río, Cuba. jlastra@upr.edu.cu
} 


\section{INTRODUCCIÓN}

La minería artesanal y a pequeña escala aplicada a la explotación de áridos constituye un medio de subsistencia para numerosos grupos poblacionales de países en vías de desarrollo. Sus implicaciones socioambientales resultan de poca atención por parte de los gobiernos e instituciones estatales, al considerarse que la magnitud de las afectaciones es insignificante al compararse con las generadas por la minería mecanizada.

La explotación artesanal y a pequeña escala de áridos en Angola tiene un carácter tradicional de antigua práctica social. Estas actividades se desarrollan principalmente en áreas situadas en las proximidades de los centros poblacionales (ciudades, poblados) y al mismo tiempo que representa una actividad económica rentable que permite el sustento de un sector significativo de la población de bajos ingresos y resuelve una significativa parte de la alta demanda de estos recursos a nivel local, su intensificación provoca impactos ambientales negativos que ponen en riesgo la estabilidad de los geosistemas naturales, la seguridad de los propios individuos que realizan la explotación, las actividades económicas y las poblaciones circundantes.

En los últimos años de reconstrucción del país en tiempos de paz este negocio fue aumentando debido al acelerado crecimiento de las construcciones, dando origen a gestores intermediarios para la comercialización de áridos en el mercado informal.

Las formas principales de explotación artesanal y a pequeña escala de los áridos en el municipio de Sumbe están vinculadas a la práctica de la extracción de arenas del cauce de los ríos, playas y dunas, con instrumentos rudimentarios, además del arranque de rocas sueltas poco consolidadas o en terrenos rocosos estratificados. En los diferentes contextos relacionados con esta actividad se destaca la participación de mujeres y niños.

En esta región, como en otras partes de Angola, estas actividades mineras se caracterizan por la anarquía, falta de control y fiscalización en la forma de extracción, almacenamiento y comercialización de estos recursos, y las condiciones en que quedan los lugares de explotación cuando son abandonados.

En consecuencia, esta investigación va dirigida a identificar y evaluar los impactos ambientales que se producen por la explotación de áridos mediante la minería artesanal y a pequeña escala en esta región, estableciendo sobre esta base las regulaciones que deben dar lugar a la explotación sostenible de estos recursos y al ordenamiento ambiental.

\section{ANTECEDENTES}

Los recursos de áridos son considerados virtualmente inagotables, excepto cuando se consideran a escalas locales (Van der Meulen, 2005). Estos habitualmente no se incluyen en los debates de sostenibilidad debido a que en raras ocasiones representan productos de importancia nacional para la exportación, como los metales y recursos energéticos (Shields y Solar, 2005). En África sub-sahariana existe un desarrollo significativo de este tipo de explotación minera, con una participación directa de diez millones de personas. La mayoría de las actividades que se desarrollan en la región es informal porque el registro es siempre costoso y burocrático (Hilson, 2016).

El sector poblacional dedicado a estas actividades está plagado de problemas que incluyen el trabajo infantil, la desigualdad de género, la propagación del VIH/SIDA, la devastación ambiental, la mala salud y seguridad, los trabajadores migrantes, la falta de capital y de mercados justos, y el conflicto con el sector privado (D’Souza, 2005; Barrantes et al., 2005; Isasi, 2008; Schuldt, 2005; Shields, 2005).

Por otra parte, la minería artesanal y a pequeña escala juegan un papel vital en la creación de empleos y alivio de pobreza, pero está acompañada por varias consecuencias sociales y medioambientales (Davies y Osano, 2005; Cante y Trujillo, 2014; De Echave et al., 2009). El problema más importante parece ser el impacto de extracción que puede provocar cambios irreversibles en el uso de la tierra y pérdida de su función si no se acomete una rehabilitación eficaz (Van der Meulen, 2005).

También se considera que este tipo de actividad minera suele tener serias repercusiones en el ecosistema, destacando que la desaparición de los bosques naturales y la consecuente erosión debido a estas actividades generan un impacto sumamente negativo en las especies vivientes de la zona (Pascó-Font et al., 1994).

De manera general, resulta común el incumplimiento de las normas y regulaciones establecidas para este tipo de actividad minera y la evasión de las 
responsabilidades individuales y colectivas para la recuperación ambiental, por lo que el papel fiscalizador de los organismos estatales resulta ineludible para el correcto desenvolvimiento de un marco legal regulatorio (Castillo et al., 2007).

A consecuencia del nivel de informalidad de la minería artesanal se origina un impacto social negativo, cuyo efecto inmediato es impedir que las autoridades gubernamentales cuenten con ingresos tributarios (Duarte, 2012).

Una de las herramientas que se puede usar para asegurar que estos recursos minerales se proporcionen de una manera que contribuya a la sostenibilidad es la gestión del recurso mineral sostenible (Shields y Solar, 2005).

\section{LOCALIZACIÓN Y CONTEXTO GEOLÓGICO}

El municipio de Sumbe, provincia de Cuanza Sul, posee un área de $3890 \mathrm{~km}^{2}$ y cerca de 218 mil habitantes. Delimita al norte con el río Queve, al sur con el río Balombo, al oeste con el Océano Atlántico, y al este con los municipios de Conda (en el poblado de Cuacra) y Uku Seles (FIGURA 1).

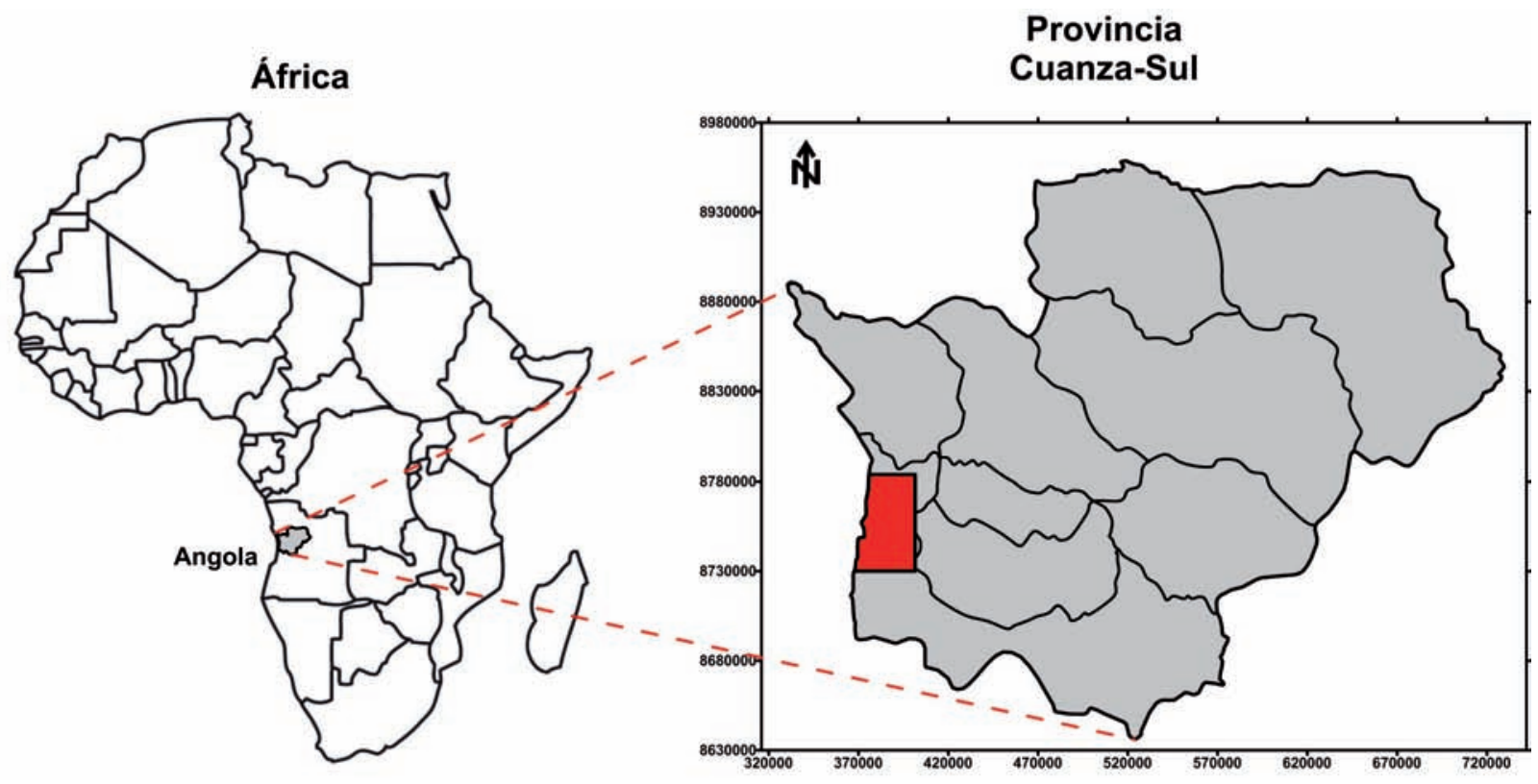

FIGURA 1. Localización geográfica de la región de estudio.

Galvão (1973) realizó una generalización de la información de los levantamientos geológicos ejecutados por Galvão (1968-1970 y 1972-1973) de la Cuenca de Benguela. Como resultado final de la recopilación de datos y su integración, obtuvo el Esbozo Geológico a escala 1:250 000 (FIGURA 2).

Las formaciones sedimentarias más antiguas corresponden al Cretácico (Aptiano Inferior) y yacen discordantemente sobre el Complejo de Base $\left(A_{1}\right)$. Están representadas reducidamente por arcillas laminadas con capas de yeso $\left(\mathrm{C}_{2}\right)$. Estas son suprayacidas concordantemente por la Formación
Binga (Aptiano Superior), constituida por calizas oolíticas y calizas subcristalinas $\left(\mathrm{C}_{3}\right)$, definiendo casi siempre una altura pronunciada a lo largo de la costa.

En la secuencia estratigráfica continúan yaciendo concordantemente rocas del Albiano Inferior representadas por areniscas y conglomerados, con afloramientos de margas arcillosas e intercalaciones de yeso y anhidrita $\left(\mathrm{C}_{4}\right)$. Sobre estas yacen los depósitos de la Formación Quissonde (Albiano Medio-Superior), constituidos por calizas oolíticas, calizas dolomíticas, dolomías y calcarenitas $\left(\mathrm{C}_{6}\right)$. 


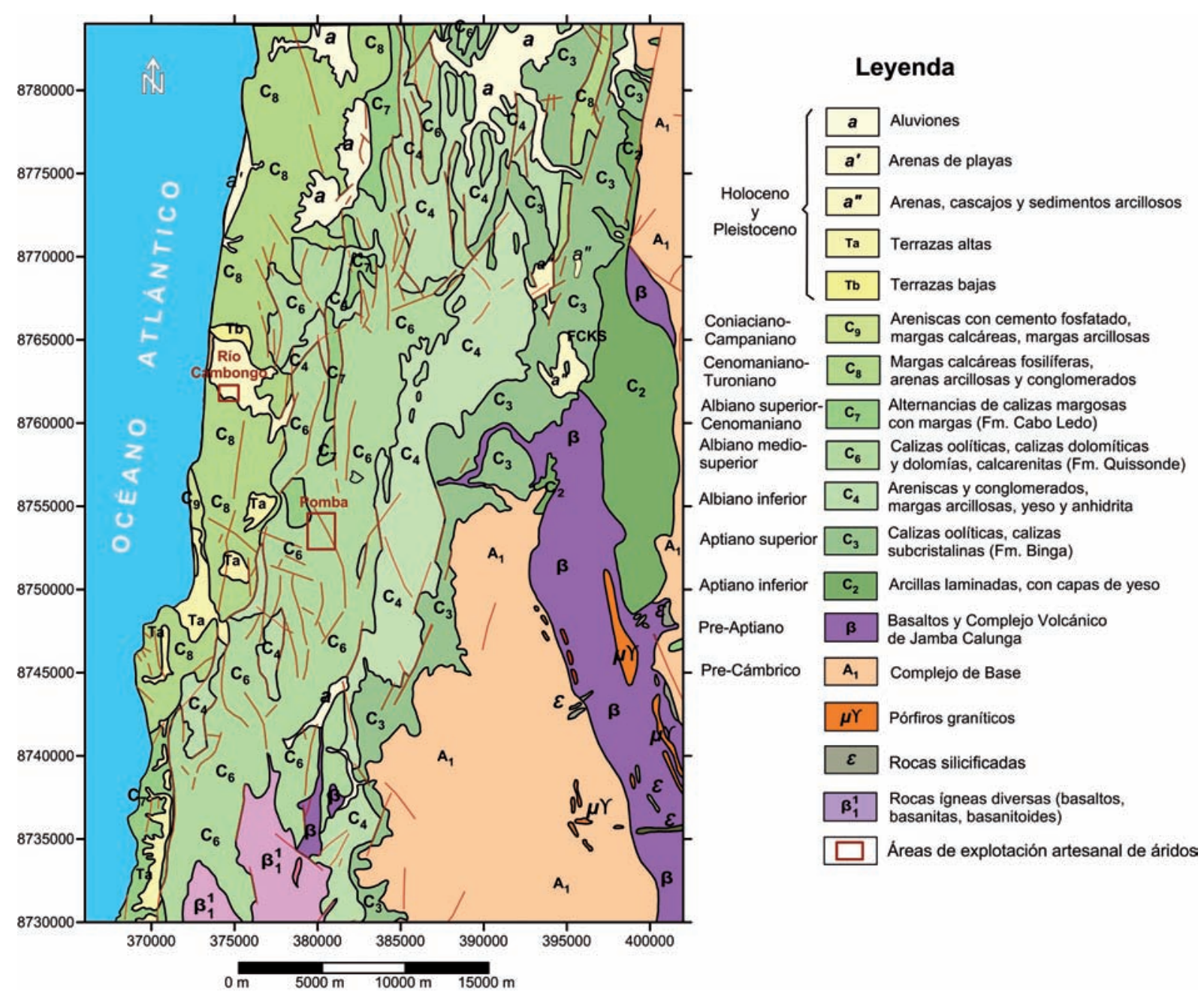

FIGURA 2. Mapa geológico de la región de estudio (Galvão, 1973) y ubicación de las áreas de explotación artesanal de áridos.

La Formación Cabo Ledo (Albiano SuperiorCenomaniano) yace concordantemente sobre la Formación Quissonde. Está representada por alternancias de calizas margosas y margas $\left(\mathrm{C}_{7}\right)$.

Continúan en el corte estratigráfico secuencias del Cenomaniano-Turoniano, que se distinguen por la presencia de capas de margas calcáreas fosilíferas, arenas arcillosas y conglomerados, con gran desarrollo en el sentido norte-sur, paralelamente a la zona litoral $\left(\mathrm{C}_{8}\right)$.

Los depósitos sedimentarios del ConiacianoCampaniano están constituidos fundamentalmente por areniscas con cemento fosfatado, margas calcáreas y margas arcillosas $\left(\mathrm{C}_{9}\right)$.
Las formaciones sedimentarias del Holoceno y Pleistoceno yacen discordantemente sobre las formaciones cretácicas más recientes. Estas se encuentran depositadas sobre la plataforma pleistocénica en las proximidades de la zona litoral, formando las denominadas terrazas bajas $(\mathrm{Tb})$ y terrazas altas $(\mathrm{Ta})$. También se describen mantos de arenas de playas no consolidadas (a'), cubriendo depósitos aluviales representados por arenas, cascajos y sedimentos arcillosos. Aluviones representados por depósitos de arena cuarzosa se encuentran en la zona litoral y hacia el interior, vinculados a zonas de deposición fluvial.

Las características litológicas descritas le confieren al territorio un elevado potencial para la explotación de áridos. 


\section{METODOLOGÍA}

Para darle cumplimiento al objetivo de este trabajo son utilizados varias herramientas, procedimientos y métodos, para cada actividad extractiva de áridos, dentro de los que se incluyen: a) métodos de campo; b) aplicación de instrumentos de investigación (encuestas-entrevistas); c) identificación y evaluación de los impactos ambientales.

a) Métodos de campo

Estos se basan en la caracterización integral de los sitios en que se realizan las actividades extractivas, teniendo en cuenta para ello: la localización físico-geográfica, la situación geológica y la descripción de las actividades vinculadas con la explotación de áridos.

También se incluye la valoración de los componentes ambientales correspondientes a cada medio (físico, biótico y socio-económico), mediante el reconocimiento en el terreno de los impactos ambientales.

b) Instrumentos de encuesta-entrevista Estos procedimientos estuvieron orientados a obtener información de los mineros ilegales, autoridades comunitarias y población vinculada a estas actividades, acerca de la percepción que poseen sobre los riesgos y peligros ambientales a los que están expuestos.
En esta acción participaron cuatro profesores y veinte estudiantes que integraron un grupo de investigación de proyecto socio-espacial del Departamento de Ciencias de la Naturaleza, Instituto de Ciencias de la Educación de Cuanza Sul.

También se contó con la contribución primaria de las autoridades tradicionales para que explicaran cómo se desarrollaba la actividad extractiva.

c) Métodos para la identificación, caracterización y evaluación de los impactos ambientales

La conjunción de las observaciones y descripciones del terreno en que se ejecutan las extracciones de áridos con la información obtenida al aplicar los instrumentos de encuesta-entrevista, posibilitan la identificación, caracterización y evaluación de los impactos ambientales.

Conesa (1995) propone varios criterios de evaluación de los impactos ambientales, a los que se les asignan categorías en correspondencia con sus niveles de influencia. Estos incluyen: signo (+/-), intensidad (IN), extensión (EX), momento (MO), persistencia (PE), reversibilidad (RV), recuperabilidad (MC), sinergia (SI), acumulación (AC), efecto (EF) y periodicidad (PR) (TABLA 1).

TABLA 1. Criterios para la evaluación de los impactos ambientales (Conesa, 1995).

\begin{tabular}{|c|c|c|}
\hline Criterios & & Significado \\
\hline Signo & $+/-$ & $\begin{array}{l}\text { Carácter benéfico }(+) \text { o perjudicial (-) de las distintas acciones que van a actuar sobre los distintos fac- } \\
\text { tores considerados. }\end{array}$ \\
\hline Intensidad & IN & Grado de incidencia de la acción sobre el factor en el ámbito específico en el que actúa. \\
\hline Extensión & EX & $\begin{array}{l}\text { Área de influencia teórica del impacto en relación con el entorno de la actividad (\% de área, respecto al } \\
\text { entorno, en que se manifiesta el efecto). }\end{array}$ \\
\hline Momento & $\mathrm{MO}$ & $\begin{array}{l}\text { Tiempo entre la aparición de la acción que produce el impacto y el comienzo de las afectaciones sobre } \\
\text { el factor considerado. Si el tiempo transcurrido es nulo, el momento será Inmediato, y si es inferior a un } \\
\text { año, Corto plazo, asignándole en ambos casos un valor de cuatro (4). Si es un período de tiempo mayor } \\
\text { a cinco años, Largo Plazo (1). }\end{array}$ \\
\hline Persistencia & $\mathrm{PE}$ & $\begin{array}{l}\text { Tiempo que supuestamente permanecerá el efecto desde su aparición y, a partir del cual el factor afectado } \\
\text { retornaría a las condiciones iniciales previas a la acción por los medios naturales o mediante la introduc- } \\
\text { ción de medidas correctoras. }\end{array}$ \\
\hline Reversibilidad & RV & $\begin{array}{l}\text { Posibilidad de reconstrucción del factor afectado, es decir, la posibilidad de retornar a las condiciones } \\
\text { iniciales previas a la acción, por medios naturales, una vez aquella deje de actuar sobre el medio. }\end{array}$ \\
\hline Recuperabilidad & $\mathrm{MC}$ & $\begin{array}{l}\text { Posibilidad de reconstrucción, total o parcial, del factor afectado, es decir, la posibilidad de retornar a } \\
\text { las condiciones iniciales previas a la acción, por medio de la intervención humana (o sea mediante la } \\
\text { implementación de medidas de manejo ambiental). }\end{array}$ \\
\hline Sinergia & SI & $\begin{array}{l}\text { Reforzamiento de dos o más efectos simples. La componente total de la manifestación de los efectos sim- } \\
\text { ples, provocados por acciones que actúan simultáneamente, es superior a la que cabría de esperar cuando } \\
\text { las acciones que las provocan actúan de manera independiente, no simultánea. }\end{array}$ \\
\hline Acumulación & $\mathrm{AC}$ & $\begin{array}{l}\text { Incremento progresivo de la manifestación del efecto cuando persiste de forma continuada o reiterada la } \\
\text { acción que lo genera. }\end{array}$ \\
\hline Efecto & $\mathrm{EF}$ & $\begin{array}{l}\text { Relación causa-efecto, o sea, a la forma de manifestación del efecto sobre un factor, como consecuencia } \\
\text { de una acción. Puede ser directo o primario, siendo en este caso la repercusión de la acción consecuencia } \\
\text { directa de ésta, o indirecto o secundario, cuando la manifestación no es consecuencia directa de la acción, } \\
\text { sino que tiene lugar a partir de un efecto primario, actuando este como una acción de segundo orden. }\end{array}$ \\
\hline Periodicidad & PR & $\begin{array}{l}\text { Regularidad de manifestación del efecto, bien sea de manera cíclica o recurrente (efecto periódico), de } \\
\text { forma impredecible en el tiempo (efecto irregular) o constante en el tiempo (efecto continuo). }\end{array}$ \\
\hline
\end{tabular}


Estos resultados son expresados en forma de matriz y se integran para cada impacto ambiental mediante la importancia (I), según la ecuación 1:

$\mathrm{I}=3 * \mathrm{IN}+2 * \mathrm{EX}+\mathrm{MO}+\mathrm{PE}+\mathrm{RV}+\mathrm{MC}+\mathrm{SI}+\mathrm{AC}+\mathrm{EF}+\mathrm{PR}($

La importancia expresa el carácter de cada impacto ambiental y permite clasificar el nivel de los impactos ambientales mediante categorías, según:

- Inferiores a 25: impactos irrelevantes o compatibles con el ambiente

- Entre 25 y 49: impactos moderados

- Entre 50 y 75: impactos severos

- Superiores a 75: impactos críticos

\section{RESULTADOS}

Esta investigación se desarrolló sobre dos casos de estudio que caracterizan la problemática de esta actividad en el municipio de Sumbe: la explotación de arenas en el río Cambongo y la explotación de calizas Pomba (FIGURA 2).

Los resultados fundamentales obtenidos a partir de los métodos y técnicas aplicados se exponen a continuación.

\section{Explotación de arenas en el río Cambongo}

\section{Localización}

El área de explotación de arenas se localiza en la margen izquierda del curso bajo del río Cambongo, en la zona acumulativa asociada a varios meandros dentro de su llanura aluvial. Esta es colindante con barrios periféricos de la ciudad de Sumbe y limita al norte con Chingo, al sur con Kissala y Cabouqueiro, al oeste con Bairro Novo y al este con Pindo (FIGURA 3).

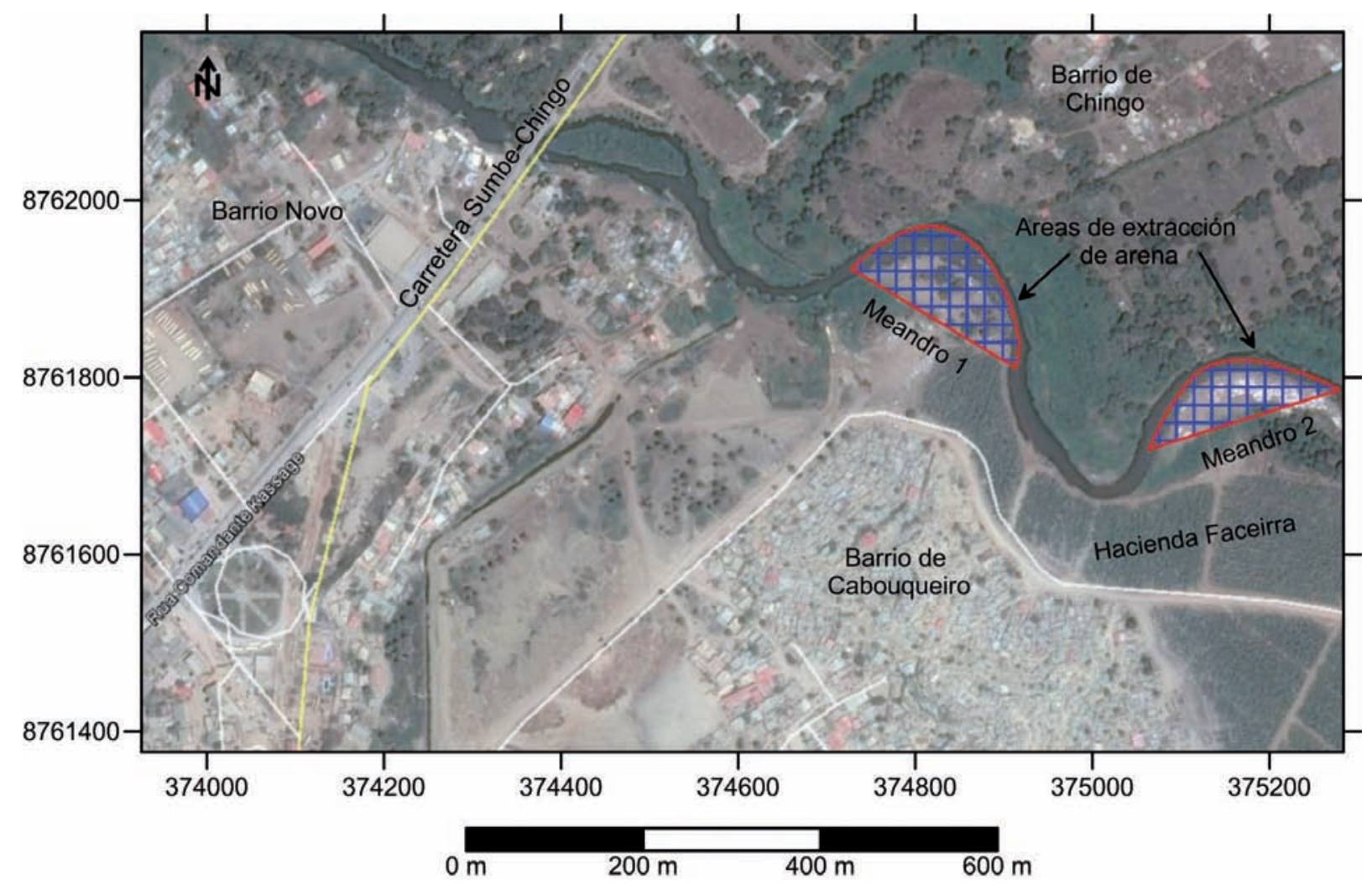

FIGURA 3. Ubicación de las áreas de explotación artesanal de arena en el río Cambongo.

\section{Caracterización integral de las actividades extractivas}

La explotación artesanal y a pequeña escala de arena en las márgenes del río Cambongo es realizada por personas y grupos familiares que no disponen de orientaciones, equipamientos y ayuda institucional para una extracción eficiente y ordenada, recurriendo a instrumentos rudimentarios, tales como: guatacas, machetes, palas, piquetas y baldes, entre otros (FIGURA 4A). 
El acopio de la arena extraída se realiza en las proximidades de la margen sur del río, en forma de pilas cónicas (montículos) (FIGURA 4B).

A estos sectores se accede para el acarreo de este material, lo que implica el acceso de vehículos de diferentes portes hasta las inmediaciones de las márgenes del río. El transporte de los áridos está dominado por grupos de hombres que compran la arena a precios concertados con las productoras y los venden a los consumidores en la zona urbana (empresas estatales o privadas) casi al doble del precio de adquisición (FIGURA 4C).
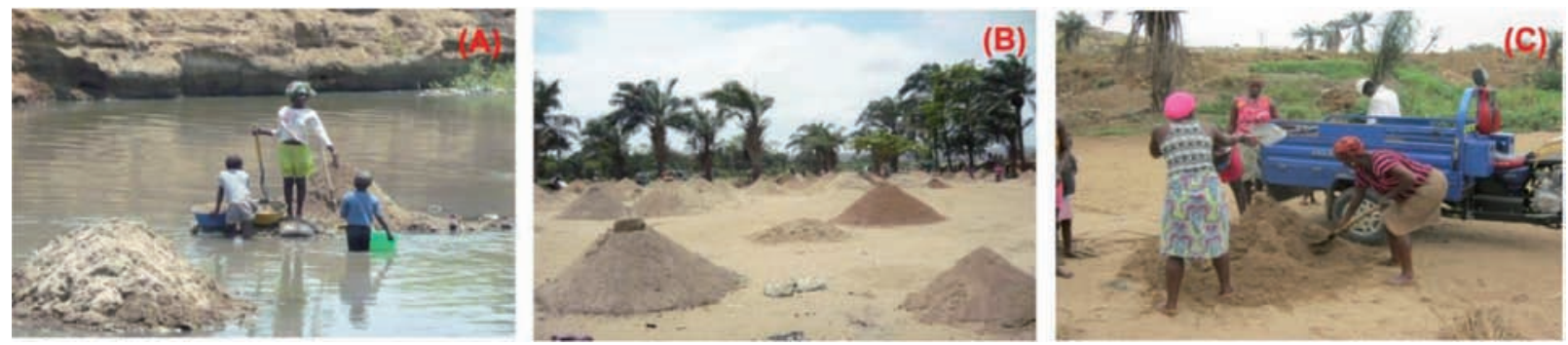

FIGURA 4. Explotación artesanal en las márgenes del río Cambongo. A. Desarrollo de la actividad extractiva por niños. B. Acopio de montículos de arena. C. Acarreo y comercialización.

No existe una percepción de los riesgos a los que están expuestos con la ejecución de estas actividades, toda vez que las mujeres y niños tienen que sumergirse hasta el fondo del río y enfrentar las corrientes de agua, lo que los convierte en vulnerables a accidentes.

Estos procesos se aceleran con las precipitaciones, el incremento de las pendientes y la falta de cobertura vegetal, resultando en el desprendimiento y transporte de grandes cantidades de rocas, guijarros, arenas y otras partículas finas (arcillas).

Esta actividad está exacerbada a partir de las demandas generadas por la construcción civil en la ciudad de Sumbe (pequeñas empresas, auto-construcciones y cambios en las viviendas tradicionales), constituyendo esta vía la más inmediata y económica para la adquisición de los materiales necesarios.

Resulta un negocio rentable para las personas y grupos familiares que participan en la extracción, transporte y comercialización de la arena extraída, sin una percepción de los daños que se están generando en las márgenes del río por los fenómenos erosivos que se intensifican con estas actividades extractivas, y sus repercusiones negativas en los campos agrícolas aledaños y las instalaciones construidas en las proximidades de los lugares de explotación.

\section{Resultados de la aplicación de los instrumentos de encuesta-entrevista}

La muestra utilizada para las encuestas y entrevistas, incluyó a 89 personas entre la población que realiza la actividad extractiva de arena en el río Cambongo, correspondiendo la inmensa mayoría a mujeres (98\%). El nivel de escolaridad es muy bajo, representado por 33 personas (37\%) analfabetas, mientras que otras 56 $(63 \%)$ alcanzan apenas el nivel básico, razón por la cual se ven obligadas a realizar esta práctica como modo de subsistencia.

En cuanto a la edad la muestra trabajada refleja que la población dedicada a esta actividad es particularmente joven, aunque abarca un rango de edades relativamente amplio: el 6\% (5 personas) entre 10 y 18 años, el 63\% (56 personas) entre 19 y 39 años y el $31 \%$ ( 28 personas) entre 40 y 69 años.

Cada familia está constituida por numerosos miembros, habitualmente entre 6 y 11 . El 25\% (22 personas) tienen algún familiar ayudando en esta actividad.

El tiempo que dedican a esta actividad es muy variado, desde personas que realizan la labor por poco tiempo ( 1 a 2 horas diarias) hasta un número significativo que permanecen durante todo el día y por etapas de tiempo prolongadas. Resulta interesante que la mayoría no presenta tradición familiar en esta actividad y más bien son obligadas a su práctica por las dificultades económicas existentes. El $55 \%$ (49 personas) tienen otra ocupación, pues no siempre durante el año es posible la extracción de arenas debido a las crecientes del río, pero la otra mitad no tienen otras opciones de trabajo, dependiendo solamente de esta actividad, que realizan con significativos riesgos. El $56 \%$ (50 personas) no poseen conocimiento de los daños ambientales que causan la extracción de 
arena del río, el 63\% (56 personas) aseguran no tener orientaciones sobre la actividad minera que realizan, el $58 \%$ (52 personas) declaran no tener condiciones para realizar su trabajo, más lo hacen por necesidad. Todos los encuestados plantean que tienen conflictos en su trabajo, principalmente debido al espacio, la lucha por los clientes y las presiones del gobierno y los compradores, entre otros, los que crea un ambiente difícil para desarrollar su labor. No obstante, el 59\% (53 personas) dicen no haber recibido sanciones o interpelaciones desde que comenzaron esta actividad, mientras el 56\% (51 personas) declararon vivir en las proximidades del área de explotación (concretamente en los barrios de Caboqueiro, Kissala 1 y Pindo).

El 91\% (81 personas) declaran que extraen entre 1 y 2 montículos $\left(1-2 \mathrm{~m}^{3}\right)$ de arena por día, lo que se considera una baja producción teniendo en cuenta el incremento de la extracción industrial, que lleva a una desigual competencia y al progresivo menosprecio de la actividad minera artesanal; así, el 46\% (41 personas) dicen sufrir humillaciones y desprecio por los agentes sociales y compradores, estando preocupados porque el negocio deje de ser rentable. En la actividad de extracción de la arena del cauce del río, los individuos encuestados utilizan en general baldes, platos y otros instrumentos rudimentarios de trabajo, que requieren una baja inversión.

Los encuestados expresaron que son diversos los tipos de clientes: comerciantes de áridos (intermediarios), poseedores de obras, empresas constructoras y población, presentando en general su producción una alta demanda.

El 75\% (67 personas) dicen estar dispuestas a mejorar el ambiente de trabajo, pero el $25 \%$ (22 personas) manifestaron no tener disposición para mejorarlo, argumentando no poseer conocimientos relacionados con el asunto. No obstante, la observación de campo del equipo investigador pudo comprobar mucha acumulación de desechos sólidos y orgánicos en torno al lugar de extracción y en el río, una parte redepositada a lo largo de sus márgenes corriente abajo y otra arrastrada hasta el litoral distante unos $2000 \mathrm{~m}$.

\section{Identificación, caracterización y evaluación de los impactos ambientales}

Como resultado de la información obtenida de las acciones ejecutadas anteriormente, fueron identificados y caracterizados los impactos ambientales, lo que se expresa brevemente a continuación:
1. Modificación morfológica. Representada por desniveles topográficos, pendientes bruscas, depresiones y montículos.

2. Desestabilización de márgenes del río. Alteración recurrente motivada por fluctuaciones de los niveles de la corriente e incremento de la erosión fluvial.

3. Alteración de la calidad del agua por partículas en suspensión. Debido a la removilización de partículas como resultado de las labores mineras en el río. Esto provoca un incremento significativo de la turbidez del agua, debido al establecimiento de suspensiones coloidales y mecánicas.

4. Alteración de la calidad del agua por aporte de residuos orgánicos. Representado por los desechos sólidos y líquidos que se vierten al río, propios de las necesidades de alimentación, higiénicas y de aseo de las personas que participan directamente en estas actividades. Todos estos residuos tienen implicaciones negativas sobre una fuente de captación de aguas que abastece la ciudad de Sumbe.

5. Transformación de la red de drenaje superficial. Se verifica más cuando cesan los procesos hidroacumulativos y escasea el agua en el cauce del río. Este es un fenómeno cíclico que está influenciado por las condiciones climáticas que imperan en diferentes épocas del año.

6. Acumulación de aguas pluviales en huecos creados. Esto se manifiesta en las márgenes del río, donde se realizan excavaciones complementarias para la extracción de arenas. Su existencia determina que en época de lluvia tiendan a mantenerse rellenas por agua.

7. Pérdida de suelo. Constituyen afectaciones a las unidades edafológicas, expresado por un perfil del suelo inmaduro y la ocurrencia de reiterados deslizamientos bajo el efecto de procesos erosivos.

8. Aparición o incremento de erosión hídrica. Imposibilita la recuperación de los horizontes superiores del suelo debido a la afectación de los regímenes normales de drenaje superficial.

9. Inestabilidad de meandros. Vulnerabilidad debido a aperturas de zanjas en las partes cóncavas del cauce del río, expuestas a la actividad extractiva.

10. Deterioro del cauce y márgenes del río. Afectaciones provocadas por extracciones de arena cíclicas y con distribución espacial irregular en las proximidades de las márgenes del río. Estas generan inestabilidad y derrumbes, con las consiguientes incidencias sobre el desarrollo del suelo y la vegetación.

11. Eliminación de cobertura vegetal en márgenes 
del río. No germina ninguna especie por retirada constante de las capas superficial.

12. Cambio del ciclo reproductivo de la vegetación. Generación de condiciones inadecuadas para un desarrollo normal de la vegetación, con tendencia a la aridez de los terrenos circundantes.

13. Destrucción de hábitat. Alteración de las condiciones naturales que garantizan la subsistencia de las especies, tales como: regímenes alimentarios, calidad de las aguas y espacios de reproducción de las especies acuáticas.

14. Disminución de la reproducción de las especies acuáticas. Efectos provocados por los cambios en el régimen reproductivo de las especies acuáticas, debido a la incorporación de agentes contaminantes a las aguas. Esto repercute sobre la biodiversidad y la población de cada especie, las que se reducen significativamente en la zona de extracción y aguas abajo.

15. Cambio en la dinámica poblacional. Irregularidades en el flujo migratorio en diferentes épocas, lo que impide el desarrollo permanente de infraestructuras sociales.

16. Riesgos de afectaciones a la salud. Potencialidades para el desarrollo de enfermedades infectocontagiosas y profesionales, sin un sistema de atención primaria de salud.

17. Incremento de la peligrosidad. Condiciones de trabajo inadecuadas que favorecen la accidentalidad, vinculada fundamentalmente con la sumersión. Las mujeres y niños que participan son más proclives a estos peligros.

18. Afectaciones de polígonos donde se practican actividades agrícolas. Ocupación de espacio habitualmente utilizado para la actividad agrícola, por lo que se afectan los ciclos de cosechas en las proximidades de las zonas de extracción y acumulación de arena.

19. Afectaciones a las ofertas de bienes y servicios. Caracterizado por la carencia de agua potable y electricidad, afectaciones a las necesidades básicas de la población, inexistencia de escuelas, ausencia de saneamiento básico, entre otros.

20. Generación de empleos temporales. Garantiza determinados niveles de subsistencia económica en una región con un bajo índice de empleo laboral.

21. Generación de expectativas. Se verifica con tendencias a mejorar la calidad de vida de la población, atendiendo a las ganancias netas que se obtienen en relación a los activos fijos empleados.

22. Cambio de capacidad de gestión de la comunidad. Transformación del mercado de empleo y de bienes y servicios.

23. Cambio en el ambiente social. Presión sobre servicios públicos básicos (educación, salud, seguridad, etc.), con influencia negativa sobre el bienestar social.

Mediante la matriz de Conesa (1995) se evalúa la importancia de estos impactos ambientales (TABLA 2).

Del análisis de los resultados mostrados en esta tabla se puede apreciar que los impactos negativos superan en importancia a los impactos positivos. Además, la totalidad de los impactos son clasificados como moderados.

\section{Explotación de calizas Pomba}

\section{Localización}

El área de explotación de calizas Pomba se localiza en los depósitos sedimentarios cretácicos de la Formación Quissonde. Limita al norte con el río Cambongo, al sur y oeste con la carretera nacional 120 que une la ciudad de Sumbe y la Villa de Seles, y al este con polígonos agropecuarios (FIGURA 5).

\section{Caracterización integral de las actividades extractivas}

La minería artesanal y a pequeña escala de calizas se realiza de manera clandestina y desordenada, aunque existe un nivel de organización del trabajo relativamente estable.

La explotación se realiza por 4 grupos familiares permanentes integrados por 18 individuos todos con residencia en la ciudad de Sumbe, algunos que permanecían durante la semana en el lugar en condiciones de viviendas rústicas y otros que preferían viajar diariamente. En general, son personas con un bajo nivel de instrucción y cada grupo está compuesto por hombres, mujeres y adolescentes. También contratan personal para hacer algunas labores que son remuneradas precariamente.

Las labores de excavación y fracturación de rocas son realizadas de manera desordenada por personas no preparadas para este tipo de actividad, provocando desniveles en el terreno, representados por zanjas y oquedades (FIGURA 6A).

Resulta común la utilización de instrumentos manuales y rudimentarios, siendo las mandarrias, picos y barretas los de mayor frecuencia (FIGURA 6B). 
Implicaciones socio-ambientales de la explotación artesanal de áridos en el municipio de Sumbe, Cuanza Sul, Angola

TABLA 2. Matriz de Conesa (1995) (área de explotación artesanal de arenas río Cambongo).

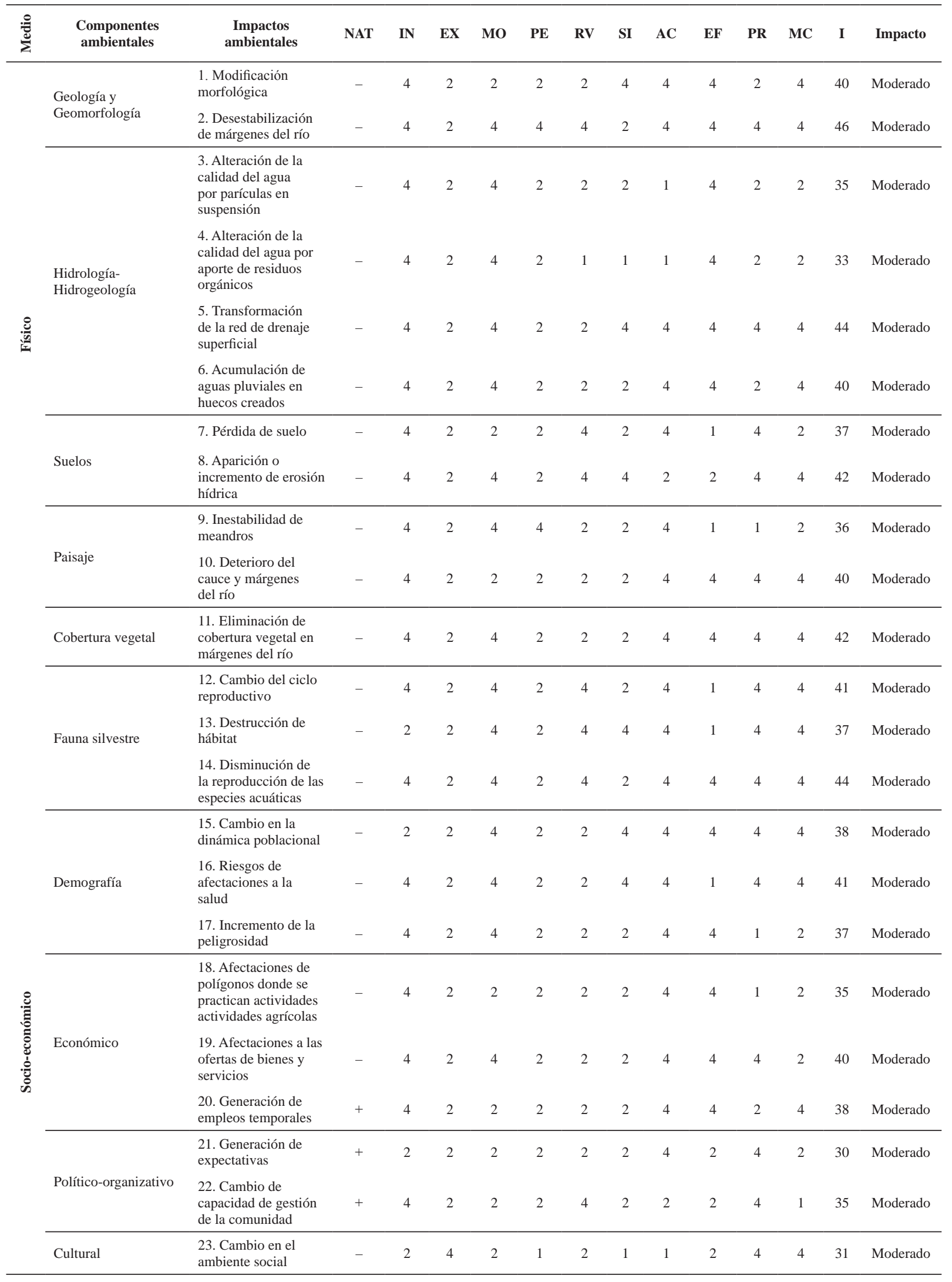




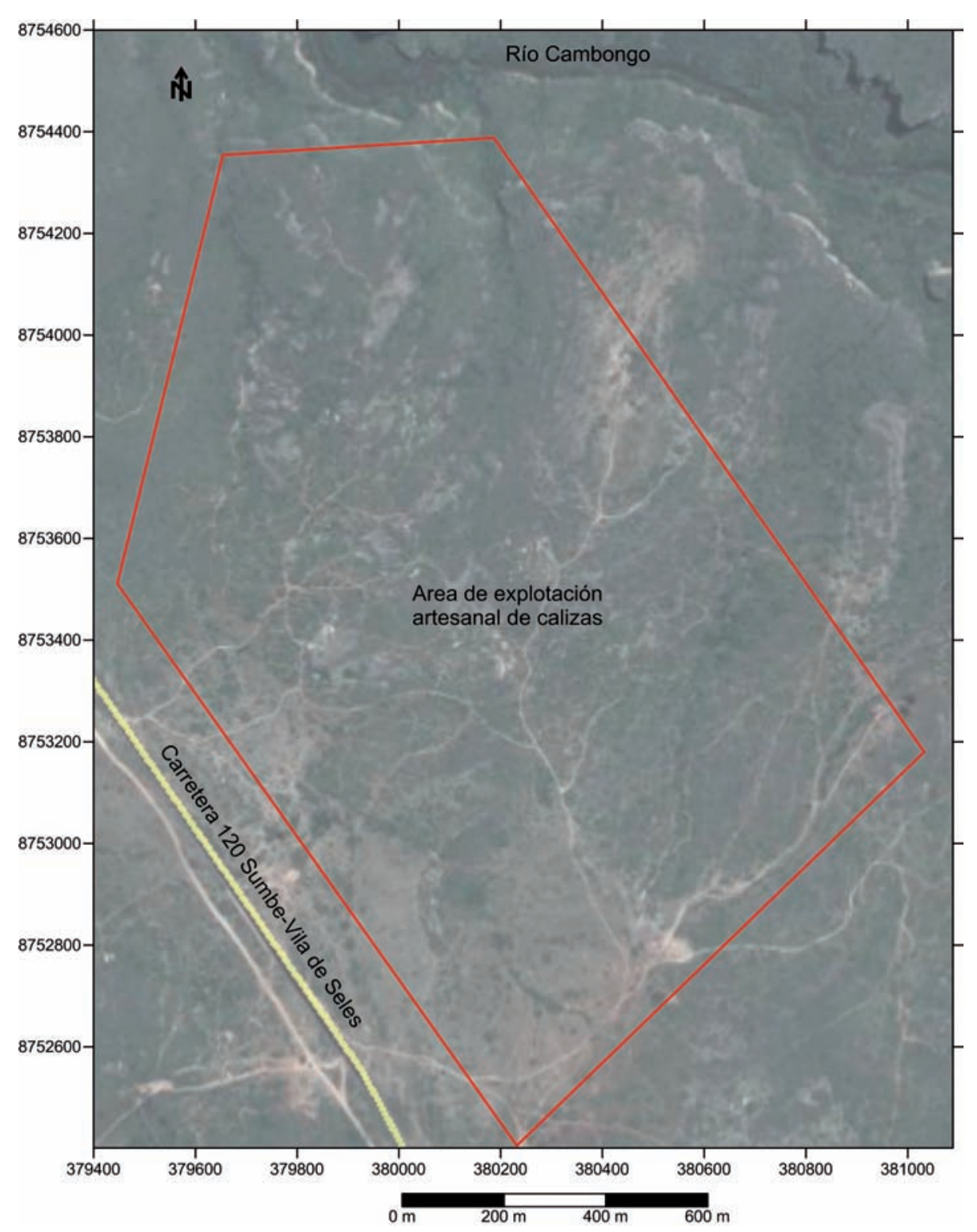

FIGURA 5. Ubicación del área de explotación artesanal de calizas Pomba.

El material extraído es acopiado en montículos, en zonas aledañas a las áreas de explotación. Estos se disponen irregularmente sobre el suelo, en espera de las personas que se encargan de su transporte y comercialización (FIGURA 6C).

La extracción clandestina de calizas en esta zona se ha intensificado debido la falta de empleo y a una gran cantidad de personas desplazadas por la guerra desde el interior del país.

Se manifiesta un desorden significativo de los lugares de explotación, dado por la resistencia de la roca a ser fracturada. Esto determina que existan movimientos de los grupos familiares de manera irregular hacia áreas donde resulte más fácil la labor artesanal de extracción de calizas. En la superficie del terreno se forman cárcavas, la mayoría de ellas en la misma dirección de la pendiente, las que se intensifican en la temporada de lluvias debido a la erosión pluvial y que a la vez, favorecen el escurrimiento superficial.

Es posible apreciar la degradación de los suelos en las áreas más explotadas, que los hace improductivos a mediano plazo. En los lugares observados donde se realiza la explotación no existen asentamientos humanos próximos, solo las viviendas rústicas de las personas que realizan este tipo de trabajo. 

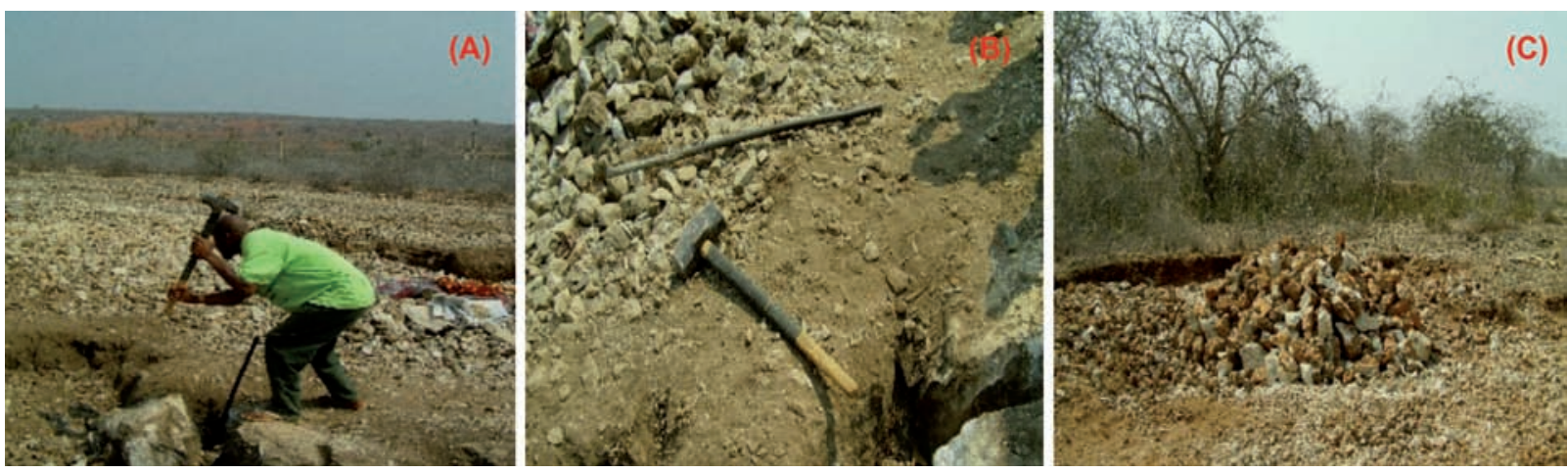

FIGURA 6. Explotación artesanal de calizas en Pomba. A. Obrero en labor de fracturación de las rocas. B. Instrumentos rudimentarios utilizados. C. Acopio del material en montículos.

\section{Resultados de la aplicación de los instrumentos de encuesta-entrevista}

La muestra a la que se le aplicó las encuestas incluyó a las 18 personas que participan permanentemente en la extracción de calizas, entre ellos 12 hombres (56\%) y 6 mujeres (44\%). También se realizaron entrevistas a cada jefe de grupo familiar, lo que permitió regularizar las informaciones vinculadas con los procedimientos y situación legal de esta actividad.

El nivel de escolaridad es sumamente bajo, representado por el 78\% (14 personas) analfabetos y el 22\% (4 personas) apenas alcanzan el nivel básico. Esto les resulta determinante para no poder acceder a otros puestos de trabajo, obligándolos a realizar estas actividades como modo de subsistencia familiar.

Las 18personas encuestadas respondieronunánimemente que las herramientas de trabajo que utilizan son rudimentarias, siendo las más utilizadas mandarrias, picos y barretas, pues son los más baratos en el mercado local. Muchos de ellos refieren que existe una tradición familiar en este tipo de actividad, considerándose que el $72 \%$ (13 personas) tenían antecedentes ancestrales.

En cuanto al tiempo de permanencia en el área de explotación, el 61\% (11 personas) refirieron que preferían viajar diariamente, mientras el $39 \%$ restante (7 personas) respondieron que permanecían durante la semana en el lugar en condiciones de viviendas rústicas.

El 56\% (10 personas) se dedican a la venta de productos agrícolas cuando no les es posible el traslado hacia el área de extracción y el otro 44\% (8 personas) manifiestan no tener otras alternativas de trabajo.

El 67\% (12 personas) no poseen noción de los daños ambientales que provoca la extracción de calizas de forma artesanal y el 33\% (6 personas) certifican que realizan estas actividades empíricamente sin poseer una preparación adecuada.

El 61\% (11 personas) exponen no tener las mínimas condiciones para efectuar la actividad extractiva y el $39 \%$ restante ( 7 personas) aprecian lo contrario.

Todas las personas encuestadas afirman que este tipo de práctica siempre genera ligeros conflictos en el hogar, entre colegas, en la comercialización, en la concertación de los precios y hasta con las autoridades gubernamentales y tradicionales. No obstante, responden que nunca fueron penalizados o interpelados durante el tiempo que se han mantenido en esta labor.

Los resultados obtenidos de la aplicación de las encuestas y entrevistas confirmaron el carácter clandestino de la extracción de calizas por estos grupos familiares, justificando estas labores como parte de la preparación de tierras con fines agropecuarios. La totalidad de los mineros argumentan que estas actividades le garantizan el sustento familiar, al lograr la comercialización del material extraído a precios acordes con las necesidades económicas más inmediatas.

Reconocen que el tiempo de explotación en un área determinada depende de la resistencia de la roca a la fracturación, aunque no perciben el daño que está provocando al patrimonio natural este cambio continuo de lugar. Indagados sobre los perjuicios ambientales que están provocando, ellos no poseen respuesta para eso y manifiestan que es la forma que tienen de lograr dinero para mantener a sus familias y que tienen que trabajar fuerte porque el precio que pagan por el material es muy bajo.

Otro factor que aceptan como influyente en la selección del área de explotación es la cercanía a la carretera, 
pues esto garantiza un acceso más regular y frecuente de los medios de transporte. Como promedio acceden de 2 a 5 camiones diarios para transportar el material extraído, aunque no se pudo lograr información directa de los conductores de estos vehículos, debido a que no aparecían o se negaban a responder a las preguntas que se le hacían. Por referencia de los mineros, ellos se convierten en intermediarios para la comercialización de estos materiales en la ciudad de Sumbe.

En cuanto al dominio de la actividad exponen que no poseen conocimientos elementales de minería, por lo que la realizan de manera empírica y desordenada. Los criterios de selección, por consiguiente, están determinados por la proximidad del material a la superficie del terreno, que facilita el proceso de extracción.

Indagados sobre los perjuicios ambientales que están provocando, no pueden dar respuesta y no existen especialistas calificados que los orienten al respecto. Ninguno fue capaz de relacionar el desarrollo de cárcavas y la denudación de los suelos con la extracción de calizas y las depresiones generadas en la superficie del terreno.

\section{Identificación, caracterización y evaluación de los impactos ambientales}

Las acciones ejecutadas anteriormente posibilitaron identificar y caracterizar los impactos ambientales, los cuales se describen a continuación:

1. Modificación morfológica. Se verifican focos de procesos erosivos, inundaciones, la construcción de rampas y taludes, huecos en rocas.

2. Desarrollo de cárcavas. El arranque irregular de fragmentos de calizas afecta el desarrollo natural del escurrimiento superficial y genera debilidad del terreno ante la circulación de las aguas pluviales. Todo ello se materializa en la formación de cárcavas que se van profundizando con el paso del tiempo.

3. Alteración de la calidad del aire. Afectaciones derivadas de la explotación y transportación del material extraído, generando nubes de polvo y gases.

4. Alteración de la calidad del agua por aporte de sedimentos. Generada por fuertes cambios hidráulicos cuando se remueve el terreno.

5. Acumulación de aguas pluviales en huecos y zanjas creados. Retención de agua de lluvia en las oquedades remanentes de la extracción de fragmentos de calizas.

6. Afectaciones en la infiltración del agua. Se vincula con la compactación del terreno debido al transporte irregular, al no existir vías de acceso predefinidas hacia y desde los sitios de extracción.

7. Pérdida de capacidad edáfica. Eliminación de las condiciones para la formación de suelo, con déficit de vegetación e incorporación de detritos derivados de la actividad extractiva.

8. Compactación del terreno. Como consecuencia del trasiego irregular del material extraído con vehículos automotores.

9. Pérdida de calidad paisajística. Detrimento de calidad visual debido al deterioro de la superficie del terreno, manifestado por oquedades irregularmente distribuidas en el espacio.

10. Eliminación y presión sobre la cobertura vegetal. Durante el arranque se elimina la cobertura vegetal inmediata al sitio de extracción y en las zonas de acopio del material extraído se oprimen los arbustos y vegetación de poco desarrollo.

11. Destrucción de hábitat. Desplazamiento de especies animales debido a la colonización de sus lugares habituales y afectaciones a sus condiciones de vida.

12. Atropellamiento de fauna. Afectaciones provocadas a la fauna autóctona debido a la circulación de vehículos.

13. Disminución de reproducción de las especies. Reducción de la biodiversidad a consecuencia de las afectaciones a sus regímenes de reproducción.

14. Cambios en la dinámica poblacional. Acumulación de pequeños grupos en el sitio de explotación abandonando sus hogares de origen.

15. Incrementos de peligros y accidentalidad. Condiciones de trabajo inadecuadas que favorecen la ocurrencia de lesiones físicas, vinculadas fundamentalmente con esfuerzos inapropiados durante el arranque, clasificación y acopio de fragmentos de calizas, sin el uso de equipos y medios de protección.

16. Riesgo de afectaciones a la salud. Vinculado con las condiciones de alimentación, acceso al agua potable, uso de viviendas rústicas, entre otras condiciones anómalas de vida, que pueden producir enfermedades infecto-contagiosas. La morbilidad puede acentuarse debido a la lejanía de centros de atención primaria de salud.

17. Desagregación poblacional. Caracterizada por dispersión de los asentamientos y falta de actividad comunitaria.

18. Generación de empleos temporales. Genera rendimiento para la subsistencia socioeconómica de las familias.

19. Afectaciones de polígonos de actividad agrícola. 
Algunas parcelas dedicadas a actividades agrícolas pueden ser agredidas por las extracciones de calizas, su acopio y transporte. Esto puede generar conflictos relacionados con el uso del suelo.

20. Cambio de capacidad de gestión de la comunidad. Transformación del mercado de empleo y de bienes y servicios.

21. Cambio en el ambiente social. Presión sobre servicios públicos básicos (educación, salud, seguridad, etc.), con influencia negativa sobre el bienestar social.
La evaluación de estos impactos ambientales se expresa mediante la aplicación de la matriz de Conesa (1995) (TABLA 3).

Como resultado fundamental derivado de esta tabla se refleja que los impactos negativos superan en importancia a los impactos positivos. Además, la mayoría de los impactos negativos son clasificados como moderados y 5 de ellos como compatibles.

TABLA 3. Matriz de Conesa (1995) (área de explotación artesanal de calizas Pomba).

\begin{tabular}{|c|c|c|c|c|c|c|c|c|c|c|c|c|c|c|c|}
\hline : & $\begin{array}{l}\text { Componentes } \\
\text { ambientales }\end{array}$ & Impactos ambientales & NAT & IN & EX & MO & PE & $\mathbf{R V}$ & SI & AC & EF & PR & MC & I & Impacto \\
\hline \multirow{10}{*}{ 莺 } & \multirow{2}{*}{$\begin{array}{l}\text { Geología y } \\
\text { Geomorfología }\end{array}$} & $\begin{array}{l}\text { 1. Modificación } \\
\text { morfológica }\end{array}$ & - & 2 & 4 & 2 & 4 & 2 & 2 & 4 & 4 & 2 & 4 & 38 & Moderado \\
\hline & & $\begin{array}{l}\text { 2. Desarrollo de } \\
\text { cárcavas }\end{array}$ & - & 2 & 4 & 2 & 2 & 2 & 2 & 1 & 4 & 2 & 4 & 33 & Moderado \\
\hline & Aire & $\begin{array}{l}\text { 3. Alteración de la } \\
\text { calidad del aire }\end{array}$ & - & 2 & 2 & 2 & 2 & 2 & 2 & 4 & 4 & 1 & 1 & 28 & Moderado \\
\hline & \multirow{3}{*}{$\begin{array}{l}\text { Hidrología- } \\
\text { Hidrogeología }\end{array}$} & $\begin{array}{l}\text { 4. Alteración de la } \\
\text { calidad del agua por } \\
\text { aporte de sedimentos }\end{array}$ & - & 1 & 2 & 2 & 2 & 2 & 2 & 1 & 4 & 2 & 4 & 26 & Moderado \\
\hline & & $\begin{array}{l}\text { 5. Acumulación } \\
\text { de aguas pluviales } \\
\text { en huecos y zanjas } \\
\text { creados }\end{array}$ & - & 4 & 2 & 2 & 2 & 2 & 2 & 4 & 4 & 2 & 4 & 38 & Moderado \\
\hline & & $\begin{array}{l}\text { 6. Afectaciones en la } \\
\text { infiltración del agua }\end{array}$ & - & 2 & 2 & 2 & 2 & 2 & 2 & 1 & 4 & 2 & 4 & 29 & Moderado \\
\hline & \multirow{2}{*}{ Suelos } & $\begin{array}{l}\text { 7. Pérdida de } \\
\text { capacidad edáfica }\end{array}$ & - & 4 & 2 & 4 & 2 & 2 & 2 & 4 & 4 & 2 & 4 & 40 & Moderado \\
\hline & & $\begin{array}{l}\text { 8. Compactación del } \\
\text { terreno }\end{array}$ & - & 4 & 2 & 2 & 2 & 2 & 2 & 4 & 4 & 2 & 4 & 38 & Moderado \\
\hline & Paisaje & $\begin{array}{l}\text { 9. Pérdida de calidad } \\
\text { paisajística }\end{array}$ & - & 4 & 4 & 4 & 2 & 2 & 2 & 4 & 4 & 2 & 4 & 44 & Moderado \\
\hline & Cobertura vegetal & $\begin{array}{l}\text { 10. Eliminación } \\
\text { y presión sobre la } \\
\text { cobertura vegetal }\end{array}$ & - & 4 & 4 & 2 & 2 & 2 & 2 & 4 & 4 & 2 & 4 & 42 & Moderado \\
\hline \multirow{6}{*}{ : } & \multirow{3}{*}{ Fauna silvestre } & $\begin{array}{l}\text { 11. Destrucción de } \\
\text { hábitat }\end{array}$ & - & 2 & 2 & 2 & 2 & 2 & 2 & 4 & 4 & 2 & 4 & 32 & Moderado \\
\hline & & $\begin{array}{l}\text { 12. Atropellamiento } \\
\text { de fauna }\end{array}$ & - & 2 & 2 & 2 & 2 & 2 & 2 & 4 & 4 & 2 & 4 & 32 & Moderado \\
\hline & & $\begin{array}{l}\text { 13. Disminución de } \\
\text { reproducción de las } \\
\text { especies }\end{array}$ & - & 2 & 4 & 2 & 2 & 2 & 2 & 4 & 4 & 2 & 4 & 36 & Moderado \\
\hline & & $\begin{array}{l}\text { 14. Cambios en la } \\
\text { dinámica poblacional }\end{array}$ & - & 4 & 2 & 1 & 1 & 1 & 1 & 1 & 1 & 1 & 1 & 24 & Compatible \\
\hline & Demografía & $\begin{array}{l}\text { 15. Incrementos } \\
\text { de peligros y } \\
\text { accidentalidad }\end{array}$ & - & 2 & 2 & 2 & 2 & 2 & 2 & 4 & 4 & 2 & 4 & 32 & Moderado \\
\hline & & $\begin{array}{l}\text { 16. Riesgo de } \\
\text { afectaciones a la salud }\end{array}$ & - & 2 & 2 & 2 & 2 & 2 & 2 & 4 & 4 & 2 & 4 & 32 & Moderado \\
\hline \multirow{5}{*}{ 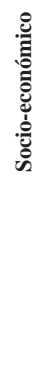 } & Espacial & $\begin{array}{l}\text { 17. Desagregación } \\
\text { poblacional }\end{array}$ & - & 3 & 1 & 1 & 1 & 1 & 1 & 1 & 1 & 1 & 1 & 19 & Compatible \\
\hline & \multirow{3}{*}{ Económico } & $\begin{array}{l}\text { 18. Generación de } \\
\text { empleos temporales }\end{array}$ & + & 2 & 1 & 1 & 1 & 1 & 1 & 1 & 1 & 1 & 1 & 16 & Compatible \\
\hline & & $\begin{array}{l}\text { 19. Afectaciones de } \\
\text { polígonos de actividad } \\
\text { agrícola }\end{array}$ & - & 4 & 4 & 2 & 2 & 2 & 2 & 4 & 4 & 2 & 4 & 42 & Moderado \\
\hline & & $\begin{array}{l}\text { 20. Cambio de } \\
\text { capacidad de gestión } \\
\text { de la comunidad }\end{array}$ & + & 2 & 1 & 1 & 1 & 1 & 1 & 1 & 1 & 1 & 1 & 16 & Compatible \\
\hline & Cultural & $\begin{array}{l}\text { 21. Cambio en el } \\
\text { ambiente social }\end{array}$ & - & 2 & 1 & 1 & 1 & 1 & 1 & 1 & 1 & 1 & 1 & 16 & Compatible \\
\hline
\end{tabular}




\section{DISCUSIÓN}

\section{Principales problemas socio-ambientales detectados}

La minería artesanal y a pequeña escala representa un aporte significativo y necesario al desarrollo socio-económico del municipio de Sumbe y es fuente de empleo e inclusión para un importante sector poblacional desfavorecido y necesitado de ayuda. Sin embargo, los problemas socio-ambientales generados superan los beneficios que se derivan, destacándose entre ellos:

- Insuficientes conocimientos técnicos de las personas que participan en las labores de explotación y comercialización de áridos, así como sus consecuencias para el medio ambiente.

- Ausencia de un programa gubernamental dirigido a la formación técnica y ambientalista de las personas dedicadas a estas actividades mineras.

- Inexistencia de normativas que garanticen la organización, regulación y fiscalización de las actividades mineras.

- Carácter irregular e ilegal imperante en la explotación de áridos.

- Utilización de mano de obra infantil en la actividad productiva.

- Exposición de las personas a problemas de salud y riesgos propios de la actividad extractiva.

- Falta de voluntad por parte de las instituciones estatales para el ordenamiento de la minería artesanal, dirigida a la solución de los problemas constructivos del territorio.

- Afectaciones a los suelos, fauna, vegetación y aguas superficiales en las zonas de extracción de áridos y áreas circundantes.

- Incidencias morfológicas sobre el terreno y en las márgenes y cauce del río Cambongo.

- Desconocimiento de las normativas y leyes establecidas en el país para el desarrollo de actividades mineras y rehabilitación ambiental de las áreas abandonadas.

\section{Estrategia para el ordenamiento ambiental}

Se demuestra en esta investigación que la explotación de áridos mediante la minería artesanal y a pequeña escala es consecuencia de la inestabilidad económica. Sus efectos se reflejan en afectaciones ambientales que no son remediadas, debido a su carácter ilegal y al desconocimiento del ordenamiento jurídico establecido para la ejecución de actividades mineras y rehabilitación de las áreas degradadas por estas.

En correspondencia con las situaciones detectadas se impone la adopción de un conjunto de medidas que contribuyan al perfeccionamiento de las actividades mineras, desde un marco legal regulatorio, y el cumplimiento de las legislaciones sobre la explotación infantil y la conservación del medio ambiente. Estas medidas se declaran a continuación:

- Creación de grupos o cooperativas para la explotación de áridos, constituidas por personas aptas física y psicológicamente para este tipo de actividad.

- Otorgamiento de concesiones mineras fiscalizadas por los organismos estatales competentes, definiendo contratos de arrendamiento por tiempo determinado y los deberes y derechos de los concesionarios.

- Elaboración e implementación de normativas y regulaciones para la actividad minera artesanal y a pequeña escala, que incluyan el derecho a la atención médica sistemática y el cumplimiento de las medidas de seguridad del trabajo.

- Establecimiento de un sistema impositivo y tributario a los concesionarios autorizados.

- Asesoramiento técnico a los mineros sobre métodos de explotación de áridos y rehabilitación ambiental para los grupos y cooperativas que participen en estas actividades.

- Creación de un sistema de educación ambiental dirigido a las personas implicadas directamente en las actividades mineras y a sus familias, en la que se integren armónicamente las ideas de los centros educacionales del territorio y las normativas a hacer cumplir al respecto por las dependencias gubernamentales.

- Activación de grupos de trabajo especializados dirigidos a la fiscalización y supervisión de las actividades mineras y los impactos ambientales generados, que apoyen a los organismos estatales encargados de velar por las atribuciones conferidas a los concesionarios a través de los contratos de arrendamiento.

- Definición de la obligatoriedad de los concesionarios de rehabilitar las áreas degradadas por la actividad minera antes de su abandono.

- Aplicación de medidas correctivas y judiciales a los infractores de la legislación vigente, con énfasis en los que utilicen mano de obra infantil. 


\section{CONCLUSIONES}

Durante las observaciones de campo, con el apoyo de entrevistas y encuestas, se logra una caracterización integral de la minería artesanal y a pequeña escala en el territorio, como base para la identificación y evaluación de los impactos ambientales generados. Se destacan las condiciones irregulares de vida de las personas dedicadas a esta actividad, la participación de mujeres y niños, el uso de herramientas rudimentarias, los riesgos y peligros a los que se enfrentan a diario, el comercio irregular de los productos extraídos, el insuficiente conocimiento de las técnicas mineras y de educación ambiental.

Los impactos ambientales identificados poseen su mayor expresividad en el relieve, geología, red hídrica, paisajes y flora y fauna de la localidad, caracterizada por la elevada fragilidad del medio ambiente ante este tipo de actividades mineras.

La carencia de un sistema de control de las operaciones mineras, con participación de las autoridades gubernamentales del territorio y el apoyo de grupos de trabajo, imposibilita el cumplimiento de las normas y regulaciones contenidas en el artículo 21 de la Ley de Minas aprobada por la Asamblea Nacional de la República de Angola (Ley No. 1/92).

Mediante la aplicación de la matriz de Conesa (1995) se pudo caracterizar la naturaleza e importancia de los impactos ambientales identificados, lo que sirvió de referencia para su evaluación. Esto permite orientar de forma más precisa las acciones a ejecutar para la mitigación de los impactos ambientales negativos, que a pesar de ser clasificados en su mayoría como moderados en la actualidad requieren de atención y control por parte de las autoridades para el ordenamiento ambiental futuro. Se debe considerar la aplicación de técnicas de análisis multitemporal de las condiciones de acumulación de sedimentos y erosión de las márgenes del río Cambongo, así como de los procesos erosivos que se activan por la explotación de calizas en el área de Pomba.

Las medidas propuestas para el ordenamiento ambiental están dirigidas a potenciar el sistema de fiscalización de las actividades extractivas y su impacto en el desarrollo socio-económico del municipio de Sumbe.

\section{AGRADECIMIENTOS}

Los autores desean dejar constancia de su agradecimiento al grupo de investigación de proyecto socio-espacial del Departamento de Ciencias de la Naturaleza, Instituto de Ciencias de la Educación de Cuanza Sul y a las autoridades tradicionales del municipio de Sumbe, por su colaboración en la aplicación de los instrumentos de encuestas-entrevistas y trabajos de campo. En igual medida al Departamento de Geología de la Universidad de Pinar del Río por la colaboración brindada en el procesamiento e interpretación de la información resultante de esta investigación.

También expresan su gratitud y reconocimiento a los especialistas que en el cumplimiento de su responsabilidad como revisores emitieron críticas, opiniones y sugerencias, todas con un elevado nivel profesional y que contribuyeron a mejorar significativamente la versión original de este documento.

\section{REFERENCIAS}

Barrantes, R., Zárate, P., y Durand, A. (2005). “Te quiero pero no": minería, desarrollo y poblaciones locales. Lima: Instituto de estudios PeruanosOXFAM.

Cante, F., y Trujillo, L. (2014). Posibilidades de gobernabilidad y gobernanza en distintos tipos de minería. Opera, 14, 27-45.

Castillo, P., Diez, A., Burneo, Z., Urrutia, J., y del Valle P. (2007). ¿Qué sabemos de las comunidades campesinas? Lima: Grupo Allpa. Comunidades y Desarrollo.

Conesa, V. (1995). Guía metodológica para la evaluación del impacto ambiental. 2da. Ed., Madrid: Ediciones Mundi-Prensa.

Davies, T.C., and Osano, O. (2005). Sustainable mineral development: case study from Kenya. Geological Society, London, Special Publications, 250, 87-93.

D’Souza, K.P.C.J. (2005). Artisanal and small-scale mining in Africa: the poor relation. Geological Society, London, Special Publications, 250, 95120. 
De Echave, J., Diez, A., Huber, L., Revesz, B., Ricard, X., y Tanaka, M. (2009). Minería y conflicto social. Lima: Instituto de Estudios Peruanos, Serie: Minería y Sociedad.

Duarte, C. (2012). Gobernabilidad minera: Cronologías legislativas del subsuelo en Colombia. Consultado el 29 de agosto de 2014. http://gobernabilidadminera. wordpress.com

Galvão, L. (1973). Esboço geológico da bacia sedimentar de Benguela a escala 1:250 000 . Direcção Provincial dos Serviços de Geologia e Minas, Luanda.

Hilson, G. (2016). Artisanal and small-scale mining and agriculture. Exploring their links in rural sub-Saharan Africa. International Institute for Environment and Development, London. 24 p.

Isasi, F. (2008). Minería en el Perú. Ministerio de Energía y Minas. Consultado el 10 de agosto de 2010. http://www.minem.gob.pe/minem/archivos/ file/institucional/publicaciones/presentaciones/ exposicion_minas_espa.pdf.

Pascó-Font, A., Trillo, A., Llosa, G., y Naranjo, G. (1994). Estudio de la minería informal y el medio ambiente (Sub-proyecto MIMA), Zona: Madre de Dios. Programa de Asistencia Técnica al Sector Energía y Minas: Lima.
Schuldt, J. (2005). ¿Somos pobres porque somos ricos?: Recursos naturales, tecnología y globalización. Lima: Fondo Editorial del Congreso del Perú.

Shields, D.J. (2005). USA and UN Perspectives on Indicators of Sustainability for the Mineral Extraction Industry. In: R.C. Villas-Bôas, D. Shields, S. Solar, P. Anciaux, G. Önal (ed.). A Review on Indicators of Sustainability for the Mineral Extraction Industries (pp. 19-30). Rio de Janeiro: CETEM/MCT/CNPq/CYTED/IMPC.

Shields, D.J., and Solar, S.V. (2005). Sustainable development and minerals: measuring mining's contribution to society. Geological Society, London, Special Publications, 250, 195-211.

Van der Meulen, M.J. (2005). Sustainable mineral development: possibilities and pitfalls illustrated by the rise and fall of Dutch mineral planning. Geological Society, London, Special Publications, 250, 225-232.

\begin{tabular}{c}
\hline \hline Januário Cacilda André \\
ORCID: 0000-0001-8892-2576 \\
José Francisco Lastra-Rivero \\
ORCID: 0000-0002-1783-0946 \\
\hline \hline
\end{tabular}

Trabajo recibido: junio 06 de 2018

Trabajo aceptado: agosto 30 de 2019 